\title{
FUNGSI SASTRA LISAN BANJAR TATANGAR
}

\section{FUNCTIONS OF ORAL LITERATURE BANJAR TATANGAR}

\author{
Hestiyana \\ Balai Bahasa Kalimantan Selatan \\ Jalan Jenderal A.Yani Km 32,2 Loktabat Utara, Banjarbaru \\ Kalimantan Selatan 70712 \\ Pos-el: hestiyana21@gmail.com
}

\begin{abstract}
Abstrak
Penelitian ini membahas masalah fungsi sastra lisan Banjar tatangar dengan tujuan untuk mendeskripsikan fungsi sastra lisan Banjar tatangar. Metode yang digunakan dalam penelitian ini adalah metode deskriptif kualitatif. Teknik yang dilakukan untuk mengumpulkan data adalah dokumentasi, rekaman, dan wawancara. Selanjutnya, dalam teknik analisis data digunakan analisis deskriptif, yaitu dengan menganalisis satu per satu tatangar tersebut sesuai dengan fungsinya. Sumber data dalam penelitian ini menggunakan: (1) data primer, yaitu informan di lapangan sebanyak 3 orang yang dikategorikan sebagai penutur sastra lisan Banjar tatangar yang bertempat tinggal di Kabupaten Hulu Sungai Selatan, Kabupaten Hulu Sungai Tengah, dan Kabupaten Hulu Sungai Utara; dan (2) data sekunder, yaitu data pelengkap yang diperoleh dari hasil penelitian yang sudah ada yang terkait dengan penelitian sastra lisan Banjar tatangar. Berdasarkan hasil analisis ditemukan ada empat fungsi sastra lisan Banjar tatangar, yaitu: (1) fungsi tatangar sebagai sebuah bentuk hiburan; (2) fungsi tatangar sebagai alat pengesahan pranata-pranata dan lembaga-lembaga kebudayaan; (3) fungsi tatangar sebagai alat pendidikan anak-anak; dan (4) fungsi tatangar sebagai alat pemaksa dan pengawas agar norma-norma masyarakat akan dipatuhi anggota kolektifnya.
\end{abstract}

Kata-kata kunci: fungsi, sastra lisan Banjar, tatangar

\begin{abstract}
This study addresses the issue of oral literature Banjar tatangar function with the aim to describe the function of oral literature Banjar tatangar. The theory used is the theory of William R. Bascom. The method used in this research is descriptive qualitative method. Techniques of collecting data are the documentation, recordings, and interviews. Furthermore, in the technique of data analysis used descriptive analysis, by analyzing one by one tatangar accordance with its function. Sources of data used in this study: (1) primary data, namely informants in the field as many as three people were categorized as oral literature Banjar tatangar speakers residing in Hulu Sungai Selatan, Hulu Sungai Tengah and Hulu Sungai Utara; and (2) secondary data, ie data obtained from the complement existing research related to the study of oral literature Banjar tatangar. Based on the analysis found four functions Banjar tatangar oral literature, namely: (1) tatangar function as a form of entertainment; (2) functions as an instrument of ratification tatangar institutions and cultural institutions; (3) tatangar function as an educational tool children; and (4) tatangar function as a means of coercion and supervisors so that society's norms will be respected member of the collective.
\end{abstract}




\section{Pendahuluan}

Sastra lisan merupakan cerminan kondisi masyarakat pendukungnya. Sastra lisan sebagai bagian dari kebudayaan daerah disebarkan dan diwariskan secara turuntemurun dari mulut ke mulut. Sastra lisan sebagai bentuk ekspresi kesusastraan masyarakat tentunya tidak lepas dari pengaruh nilai-nilai yang berkembang dalam masyarakat. Sastra lisan mengandung nilai-nilai moral yang mencakup kehidupan masyarakat yang harus dipelihara dan dilestarikan. Dalam sastra lisan juga terpancar nilai, gagasan, norma-norma, kepercayaan, dan keyakinan yang dimiliki masyarakat pendukungnya.

Nurgiyantoro

mengemukakan bahwa karya sastra senantiasa menawarkan pesan moral yang berhubungan dengan sifat-sifat luhur kemanusiaan yang bersifat universal. Artinya, sifat-sifat itu dimiliki dan diyakini kebenarannya oleh manusia sejagad. Ia tidak hanya bersifat kesebangsaan, apalagi perseorangan, walaupun memang terdapat ajaran moralkesusilaan yang hanya berlaku dan diyakini oleh kelompok tertentu.

Sastra lisan menampilkan gambaran kehidupan yang menjadi refleksi kehidupan sosial yang mencakup hubungan antarmasyarakat, antarmanusia, dan antarperistiwa. Sastra lisan yang menjadi milik bersama ini mempunyai fungsi serta memiliki peranan yang berkelanjutan dalam jangka waktu lama sehingga dapat dijadikan pedoman dan membentuk norma-norma di dalam masyarakat pendukungnya.

Salah satu bentuk sastra lisan Banjar adalah tatangar. Wahana atau tatangar ini merupakan kepercayaan masyarakat Banjar yang ditandai dengan adanya firasat yang mengandung maksud tertentu. Masyarakat Banjar memercayai bahwa tatangar menjadi sebuah simbol atau tanda akan terjadinya sesuatu meskipun tatangar itu sendiri mengandung unsur ketakhayulan.

Hapip (2001:186) menyatakan bahwa tatangar adalah alamat, tandatanda (akan terjadinya sesuatu peristiwa). Pendapat yang sama juga dikemukakan Musdalipah dkk. (2008:267) bahwa tatangar adalah firasat; pertanda akan terjadinya sesuatu peristiwa. Mugeni dkk. (2009:3) juga mengemukakan bahwa tatangar adalah sastra lisan jenis takhayul dalam bentuk kalimat pernyataan yang menyimbolkan atau menandakan sesuatu.

Dengan demikian, tatangar merupakan salah satu bentuk sastra lisan Banjar yang dipercayai masyarakat Banjar sebagai tanda atau ciri yang menandakan atau memberikan firasat akan terjadinya sebuah peristiwa. Di dalam tatangar terkandung nilai-nilai yang perlu dilestarikan karena menjadi tata norma sosial di masyarakat.

Penelitian mengenai sastra lisan Banjar tatangar hingga saat ini jumlahnya masih sedikit. Penelitian tentang tatangar yang pernah dilakukan Mugeni dkk. (2008) berjudul Tatangar atau Wahana Banjar. Kajian tersebut mengategorikan tatangar atau wahana menjadi lima, yaitu: (1) tatangar yang berasal dari hewan; (2) tatangar yang berasal dari mimpi; (3) tatangar yang berasal dari alam; (4) tatangar yang berasal dari tumbuhan; dan (5) tatangar yang berasal dari manusia atau anggota tubuh. Hasil kajian tersebut hanya membatasi pada klasifikasi tatangar atau wahana.

Kajian fungsi sastra lisan Banjar tatangar ini lebih mendalam dari penelitian sebelumnya karena membahas 
fungsi sastra lisan tatangar yang masih hidup dan berkembang dalam kehidupan masyarakat Banjar serta tidak dibahas dalam penelitian sebelumnya. Selain itu, keberadaan sastra lisan Banjar tatangar yang terancam punah sehingga perlu dilakukan kajian terhadap sastra lisan tatangar tersebut. Mengingat, sastra lisan tatangar yang sarat akan pesan moral dan nilai-nilai kehidupan sosial yang harus kita lestarikan. Hal inilah yang melatarbelakangi kajian tentang fungsi sastra lisan Banjar tatangar ini.

Berdasarkan latar belakang yang telah dikemukakan, masalah yang menjadi fokus kajian ini adalah bagaimana fungsi sastra lisan Banjar tatangar? Penelitian ini bertujuan untuk mendeskripsikan fungsi sastra lisan Banjar tatangar. Manfaat penelitian ini adalah memberikan informasi dan wawasan kepada masyarakat bahwa sastra lisan memiliki banyak fungsi dan manfaat, terutama sastra lisan Banjar tatangar. Kajian sastra lisan Banjar tatangar ini juga dapat mengungkapkan kehidupan masyarakat Banjar yang dapat dijadikan pelajaran bagi generasi penerus.

Selanjutnya, hasil penelitian ini juga akan menambah kekayaan penelitian sastra lisan dan dapat dijadikan bahan serta acuan bagi penelitian selanjutnya. Selain itu, kajian sastra lisan Banjar tatangar ini sangat menarik untuk dikaji karena bermanfaat bagi teori pengkajian sastra lisan nusantara.

\section{Teori dan Metode}

\subsection{Teori}

\subsubsection{Sastra Lisan}

Sastra lisan (oral literature) adalah bagian dari tradisi lisan (oral tradition) atau yang biasa dikembangkan dalam kebudayaan lisan (oral culture) berupa pesan-pesan, cerita-cerita, atau kesaksian-kesaksian ataupun yang diwariskan secara lisan dari satu generasi ke generasi lainnya (Vansina, 1985:27). Pesan, cerita, atau kesaksian itu disampaikan melalui tuturan atau nyanyian.

Taum (2011:21) merumuskan bahwa sastra lisan adalah sekelompok teks yang disebarkan dan diturun-temurunkan secara lisan, yang secara intrinsik mengandung sarana-sarana kesusastraan dan memiliki efek estetik dalam kaitannya dengan konteks moral maupun kultural dari sekelompok masyarakat tertentu. Kemudian, dinyatakan oleh Whellwright (dalam Taum, 2011:8) bahwa sastra lisan adalah kreasi estetik dari imajinasi manusia.

Sastra lisan merupakan bagian dari tradisi lisan masyarakat pendukungnya yang diwariskan secara turun-temurun dan dituturkan dari mulut ke mulut. Sastra lisan disebut literature transmitted orally atau unwritten literature yang lebih dikenal dengan istilah folklore. Sementara Danandjaja menyebut tradisi lisan sinonim dari folklor lisan. Hal ini karena sastra lisan merupakan bagian kebudayaan yang tersebar dan diwariskan turun-temurun baik yang disertai dengan gerak isyarat atau alat pembantu pengingat (Astika, 2014:2).

Bartlett

(1965:244-245)

mengemukakan bahwa sastra lisan merupakan sastra yang diperdengarkan. Jadi, sastra lisan merupakan kekayaan daerah yang harus mendapat perhatian dan nilai-nilai yang terdapat di dalamnya harus terus pula digali. Pendapat yang sama juga dikemukakan Tuloli (dalam Amir, 2013:43) yang menyatakan bahwa sastra lisan adalah salah satu gejala kebudayaan yang terdapat pada masyarakat terpelajar dan yang belum terpelajar. Sastra lisan harus dibicarakan dalam hubungan dengan pencerita, penceritaan, dan pendengar atau penontonnya. Selanjutnya, Tuloli (dalam Amir, 2013:44) mengatakan bahwa sastra lisan berubah sesuai dengan dinamika 
masyarakat pemiliknya. Usaha pelestarian perlu dilaksanakan karena perubahan kepunahan sastra lisan tidak akan pernah berhenti. Jika sastra lisan hilang atau punah, kekayaan budaya di dalamnya akan punah pula atau berubah.

Lord (dalam Sunarti, 2013:3) menyatakan bahwa kata-kata dan barisbaris dalam komposisi cerita lisan disusun atau diciptakan oleh pencerita dengan menggunakan pola formula. Penutur mencoba mengingat frasa-frasa yang didengarnya dari penutur lain dan yang telah berkali-kali digunakan dalam menuturkan suatu cerita. Mereka menggunakan ingatan (remembering), seperti kita menggunakan secara tanpa sadar ungkapan-ungkapan dalam ucapan biasa dan bukan menggunakan hapalan (memorization).

Dengan demikian, sastra lisan merupakan hasil ekspresi kesusastraan yang disebarkan dari mulut ke mulut secara turun-temurun yang mengandung nilai-nilai moral. Dalam sastra lisan, nilai-nilai moral tersebut diyakini dapat menjadi norma-norma dalam masyarakat serta menjadi ciri budaya masyarakat pemiliknya. Sastra lisan sebagai kekayaan daerah memancarkan normanorma kehidupan yang menjadi tuntunan masyarakat pendukungnya.

Ciri-ciri kelisanan yang paling menonjol sering ditemui dalam genre sastra lisan tradisional. Finnegan (dalam Ikram, 2015:242) berpendapat bahwa sastra untuk dapat disebut lisan harus memenuhi tiga kriteria lisani, yaitu (1) segi komposisi, (2) segi transmisi, (3) segi penyajian atau pementasan. Kriteria yang ketiga tersebut tidak selalu harus di hadapan orang banyak seperti teater.

Menurut Rusyana (dalam Taum, 2011:23), ciri dasar sastra lisan ialah (1) tergantung kepada penutur, pendengar, ruang, dan waktu; (2) antara penutur dan pendengar terjadi kontak fisik, sarana komunikasi dilengkapi paralinguistik; (3) bersifat anonim. Endraswara (2013:151) juga mengemukakan bahwa ciri-ciri sastra lisan, antara lain (1) lahir dari masyarakat yang polos, belum melek huruf, dan bersifat tradisional; (2) menggambarkan budaya milik kolektif tertentu, yang tidak jelas siapa penciptanya; (3) lebih menekankan aspek khayalan, ada sindiran, jenaka, dan pesan mendidik; dan (4) sering melukiskan tradisi kolektif tertentu. Di samping ciriciri tersebut, ada ciri lain yang agak umum, yakni 1) banyak mengungkapkan kata-kata atau ungkapan-ungkapan klise dan (2) sering bersifat menggurui.

Hutomo (1991: 3--4) menyatakan bahwa sastra lisan memiliki ciri, antara lain(1) penyebarannya melalui mulut, maksudnya ekspresi budaya yang disebarkan baik dari segi waktu maupun ruang melalui mulut; (2) lahir dari masyarakat yang masih bercorak desa, masyarakat di luar kota, atau masyarakat yang belum mengenal huruf; (3) menggambarkan ciri-ciri budaya satu kelompok masyarakat; (4) bercorak puitis; (5) terdiri dari berbagai versi; (6) tidak mementingkan fakta atau kebenaran, lebih menekankan pada aspek khayalan, fantasi yang tidak diterima oleh masyarakat modern, tetapi mempunyai fungsi di masyarakat, dan (7) menggunakan bahasa lisan setiap hari.

Taum (2011:24) merumuskan lima ciri utama sastra lisan sebagai berikut: (1) sastra lisan adalah teks sastra yang dituturkan secara lisan; (2) sastra lisan hadir dalam berbagai bahasa daerah; (3) sastra lisan selalu hadir dalam versi-versi dan varian-varian yang berbeda-beda; (4) sastra lisan bertahan secara tradisional dan disebarkan dalam bentuk standar/relatif tetap dalam kurun waktu yang cukup lama, paling kurang dua generasi; dan (5) sastra lisan memiliki konvensi dan poetikanya sendiri.

Ciri-ciri sastra lisan juga disampaikan Astika (2014:4), yaitu (1) 
cara penyampaian atau penyebarannya; (2) bersifat kolektif; (3) anonim; (4) bersifat tradisional; (5) memiliki berbagai versi; (6) memiliki kegunaan atau fungsi tertentu dalam masyarakat; (7) memiliki bentuk atau pola atau formula tertentu; dan(8) memiliki sifat-sifat sastra, yaitu bermediumkan bahasa, fiksi atau tidak, nyata atau khayalan, imajinatif, bahasa yang indah atau puitis, fungsi estetis, dan berguna.

\subsubsection{Fungsi Sastra Lisan}

Sastra lisan sebagai warisan budaya memiliki fungsi-fungsi dalam masyarakat pendukungnya. Merton (dalam Wahyono, 2015:425) menyatakan bahwa fungsi adalah sesuatu yang menjadi kaitan antara satu dan hal lain atau sesuatu yang menyatakan hubungan antara suatu hal dan pemenuhan kebutuhan tertentu.

Kemudian, Durkheim (dalam Wahyono, 2015:425) memberi batasan fungsi sebagai hubungan antara suatu (pranata) dengan kebutuhan dari organisme masyarakat. Sejalan dengan itu, Herkovits (dalam Wahyono, 2015:425) menyatakan bahwa suatu pandangan fungsional berusaha untuk mempelajari saling hubungan antara berbagai unsur kecil dan besar dalam suatu kebudayaan dan dengan itu ditunjukkan kesalinghubungan tersebut berguna untuk membuat keseluruhannya berjalan.

Heddy Shri Ahimsa Putra (dalam Astika, 2014:3) berpendapat bahwa sebagai salah satu bentuk ekspresi budaya masyarakat pemiliknya, tradisi lisan tidak hanya mengandung unsurunsur keindahan (estetik), tetapi juga mengandung berbagai informasi tentang nilai-nilai kebudayaan tradisi yang bersangkutan.

Amir (2013:34) mengemukakan bahwa fungsi sastra lisan sebagai hiburan atau membuat masyarakat terhibur. Endraswara (2013:157) mengatakan bahwa sastra lisan memang kaya makna dan menghibur sekaligus mengasah otak penikmat. Di samping memuat makna dan fungsi hiburan, sastra lisan juga memuat aspek-aspek sindiran.

Dinyatakan oleh Alan Dundes (Danandjaja, 2002:45) bahwa fungsi sastra lisan dibagi menjadi lima, yaitu (1) untuk menguji kepandaian seseorang, (2) untuk meramal, (3) sebagai bagian dari upacara perkawinan, (4) untuk mengisi waktu pada saat bergadang menjaga jenazah, dan (5) untuk dapat melebihi orang lain.

Hutomo (dalam Endraswara, 2009:125) memberikan konsep fungsi ialah 'kaitan saling ketergantungan, secara utuh dan berstruktur, antara unsurunsur sastra, tulis atau lisan, baik di dalam sastra itu sendiri (intern), maupun dengan lingkungannya (ekstern), tanpa membedakan apakah unsur-unsur tersebut dipergunakan untuk memenuhi kebutuhan naluri manusia, ataupun memelihara keutuhan dan sistem struktur sosial'.

Bascom dalam Sudikan (2001:109) mengungkapkan bahwa sastra lisan (folklore lisan dan sebagian lisan) mempunyai empat fungsi, yaitu (1) sebagai sebuah bentuk hiburan (as a from amusement), (2) sebagai alat pengesahan pranata-pranata dan lembaga-lembaga kebudayaan (it plays in validating culture, in justifiying its rituals and institutions to those who perform and observe them), (3) sebagai alat pendidikan anak-anak (it plays in educations, as pedagogical device), dan (4) sebagai alat pemaksa dan pengawas agar norma-norma masyarakat akan dipatuhi anggota kolektifnya (maintaining comformity to the accepted patterns of behavior, as means of applying social pressure and excercising social control). Dari berbagai konsep teoretis fungsi di atas, penelitian ini akan mencoba menerapkan teori Bascom 
(dalam Sudikan, 2001:109) untuk mengkaji fungsi sastra lisan Banjar tatangar.

\subsection{Metode dan Teknik Penelitian \\ 2.2.1 Metode Penelitian}

Metode yang digunakan dalam penelitian ini adalah metode deskriptif dengan pendekatan kualitatif karena bertujuan untuk mengumpulkan, mengklasifikasikan, dan menganalisis data sehingga diperoleh gambaran menyeluruh tentang fungsi sastra lisan Banjartatangar. Sumber data dalam penelitian ini berupa data primer dan data sekunder. Hal ini seperti yang diungkapkan Arikunto (2006:135) yang menyatakan bahwa sumber data dapat dikelompokkan menjadi dua bagian, yakni (1) data primer, yaitu data pokok, dalam hal ini tuturan sastra lisan tatangar yang dikumpulkan dari narasumber yang diperoleh dari hasil dokumentasi, rekaman, serta wawancara; dan (2) data sekunder, yaitu data pelengkap yang diperoleh dari hasil penelitian yang sudah ada yang terkait dengan penelitian sastra lisan Banjar tatangar.

Sumber data primer dalam penelitian ini adalah informan di lapangan sebanyak tiga orang yang dikategorikan sebagai penutur sastra lisan Banjar tatangar yang bertempat tinggal di Kabupaten Hulu Sungai Selatan, Kabupaten Hulu Sungai Tengah, dan Kabupaten Hulu Sungai Utara. Hal ini mengacu kepada pendapat yang dikemukakan Endraswara (2013: 156) bahwa kajian sastra lisan seharusnya tidak hanya berhenti pada klasifikasi data di lapangan, tetapi juga harus sampai pada fungsi sastra lisan itu sendiri. Fungsi dapat dilacak dengan menggunakan penafsiran yang dapat digali dari informan. Selanjutnya, Koster (dalam Pudentia, 2015:39) menegaskan bahwa kaidah lain yang digunakan untuk menggali informasi tentang puitika sastra lisan ialah mengkaji cara teks-teks lisan yang dihasilkan oleh penutur atau dalang.

Dengan demikian, dalam mengkaji sastra lisan pentingnya menggali data dengan melibatkan informan. Dalam penelitian ini, sebelum masuk lapangan untuk mengumpulkan data, terlebih dahulu peneliti mempersiapkan diri secara konseptual dengan menentukan pertanyaan-pertanyaan yang akan memberikan pedoman dan arahan terhadap kajian fungsi sastra lisan Banjar tatangar.

\subsubsection{Teknik Penelitian}

Teknik yang dilakukan untuk mengumpulkan data adalah dokumentasi, rekaman, dan wawancara. Teknik dokumentasi dilakukan dengan melihat penelitian terdahulu yang berkaitan dengan objek yang dikaji, yaitu sastra lisan Banjar tatangar. Teknik rekaman dilakukan dengan cara merekam tuturan sastra lisan Banjar tatangar dari narasumber. Kemudian, teknik wawancara dilakukan untuk memperoleh keterangan dengan cara tanya jawab sambil bertatap muka langsung dengan narasumber. Hal ini seperti yang dikemukakan Koster (dalam Pudentia, 2015:38) bahwa untuk memperoleh informasi tentang puitika sastra lisan, kita harus melakukan kerja lapangan. Kemudian informasi itu harus terus digali dari pernyataan-pernyataan dan komentar-komentar yang diberi oleh tukang cerita ketika menyampaikan cerita atau dalam wawancara dengan peneliti.

Dalam penelitian ini dilakukan wawancara tidak berstruktur. Hal ini seperti yang diungkapkan oleh Sugiyono (2010:138) bahwa wawancara tidak berstruktur adalah wawancara bebas, peneliti tidak menggunakan pedoman wawancara yang telah tersusun secara sistematis dan lengkap untuk pengumpulan data. Pedoman wawancara yang digunakan hanya berupa garis-garis 
besar permasalahan yang akan ditanyakan dengan cara tatap muka. Dalam hal ini, wawancara tidak terstruktur dilakukan kepada narasumber dengan cara tatap muka langsung untuk memperoleh tuturan-tuturan sastra lisan Banjar tatangar. Hal mendasar yang ditanyakan kepada narasumber adalah tuturan tatangar yang masih dipercayai serta fungsinya bagi masyarakat Banjar. Selanjutnya, dalam teknik analisis data digunakan analisis deskriptif, yaitu dengan menganalisis satu per satu tatangar tersebut sesuai dengan fungsinya.

\section{Hasil dan Pembahasan}

Dalam menganalisis fungsi sastra lisan Banjar tatangar digunakan analisis fungsi Bascom (dalam Sudikan, 2001: 109) yang mengemukakan bahwa sastra lisan mempunyai empat fungsi, yaitu (1) sebagai sebuah bentuk hiburan; (2) sebagai alat pengesahan pranata-pranata dan lembaga-lembaga kebudayaan; (3) sebagai alat pendidikan anak; dan (4) sebagai alat pemaksa dan pengawas agar norma-norma masyarakat akan dipatuhi anggota kolektifnya. Berikut hasil analisis fungsi sastra lisan Banjar tatangar.

\subsection{Fungsi tatangar sebagai sebuah bentuk hiburan}

Tatangar memiliki fungsi sebagai sebuah bentuk hiburan. Sastra lisan Banjar ini meskipun dipercayai sebagai pertanda akan terjadinya sesuatu, di sisi lain juga mempunyai fungsi untuk hiburan. Berikut hasil analisisnya.

a. Lamun ada nang tamimpi masuk ka pahumaan atau dukuh buah, tandanya handak mandapat kasanangan.

"Kalau ada yang bermimpi masuk ke persawahan atau kebun buah, tandanya akan mendapat kesenangan."
Bagi masyarakat Banjar, pahumaan 'persawahan' dan dukuh buah 'kebun buah' merupakan lambang kemakmuran. Sawah dan kebun buah ini menjadi lahan mata pencaharian sehingga apabila ada yang bermimpi masuk ke persawahan atau kebun buah menjadi pertanda akan mendapat kesenangan atau kebahagiaan. Meskipun tidak ada hubungan langsung antara mimpi dan kenyataannya, tatangar ini sebagian masih dipercayai masyarakat Banjar. Tatangar ini dianggap mampu membuat yang bermimpi menjadi senang atau terhibur dengan mimpinya. Selain mempunyai fungsi untuk menghibur, tatangar ini dapat menjadi motivasi hidup bagi yang bermimpi.

b. Lamun ada bayi nang guring sambil tatawa, tandanya lagi digayai tambuninya.

"Kalau ada bayi yang tidur sambil tertawa, tandanya sedang dicandai tembuninya."

Bagi masyarakat Banjar, kalau ada bayi yang sedang tidur sambil tertawa, tandanya bayi tersebut sedang dicandai tembuninya sehingga tertawa-tawa. Masyarakat Banjar menganggap bahwa tambuni 'tembuni' adalah saudara bayi selama berada di dalam kandungan hingga lahir ke dunia. Ketika bayi lahir ke dunia, tembuninya akan dimasukkan dalam suatu wadah yang terbuat dari tanah liat. Dalam wadah tembuni tersebut juga dimasukkan berbagai macam bahan memasak seperti bawang merah dan bawang putih, serta peralatan menulis seperti buku, pensil, dan pulpen. Hal ini tergantung dari keinginan orang tua bayi yang dipercayai bahwa bayi akan menjadi seseorang yang sesuai dengan keinginan orang tua. Kemudian, wadah tembuni tersebut dikubur dan diberi lampu agar bayi merasa nyaman dan hangat.

Bayi yang baru dilahirkan, terkadang dalam keadaan tidur sering tertawa-tawa sendiri, baik siang hari ataupun malam 
hari. Hal ini membuat orang tua merasa senang melihat anaknya yang tertawatawa, bahkan orang tua juga ikut tersenyum dan terhibur melihat bayi mungilnya yang tertawa dicandai tembuninya. Tatangar ini menunjukkan fungsinya sebagai sebuah bentuk hiburan.

c. Lamun ada garis lipatan di paha bayi sabuting, tandanya cagar baisi ading lalakian.

"Kalau ada garis lipatan di paha bayi satu, tandanya akan mempunyai adik laki-laki."

Tatangar lamun ada garis lipatan di paha bayi sabuting, tandanya cagar baading lalakian "kalau ada garis lipatan di paha bayi satu, tandanya akan mempunyai adik laki-laki” juga mempunyai fungsi sebagai hiburan. Tuturan tatangar ini dijadikan sarana untuk menghibur bagi orang tua yang menginginkan anak lagi, terutama anak laki-laki. Meskipun dalam tatangar ini tidak ada hubungan langsung antara satu garis lipatan di paha bayi dengan jenis kelamin adiknya nanti, tetapi tuturan tatangar ini masih dipercayai sebagian masyarakat Banjar. Dengan adanya tuturan tatangar seperti itu mampu menunjukkan fungsinya sebagai alat hiburan bagi pasangan suami istri yang menginginkan anak laki-laki. Akan tetapi, selain percaya dengan tatangar itu biasanya pasangan suami istri juga berusaha dan berdoa agar keinginannya terkabul.

\subsection{Fungsi tatangar sebagai alat pengesahan pranata-pranata dan lembaga-lembaga kebudayaan}

Tatangar juga mempunyai fungsi sebagai alat pengesahan pranata-pranata dan lembaga-lembaga kebudayaan bagi masyarakat Banjar. Berikut hasil analisisnya.

a. Lamun haratan guring tali kalambu pagat, tandanya ada urang nang mangirim parang maya.

"Kalau sedang tidur tali kelambu putus, tandanya ada orang yang mengirim tenung."

Masyarakat Banjar begitu memercayai tatangar kalau seseorang yang sedang tidur tiba-tiba tali kelambu putus, itu merupakan pertanda ada orang yang mengirim tenung. Dari dulu, kelambu dijadikan sebagai penangkal kejahatan yang berupa gaib, seperti tenung. Apabila seseorang yang sedang tidur mendapati kelambunya putus, orang tersebut jangan langsung keluar dari kelambu. Hal ini dipercayai masyarakat Banjar akan membawa celaka bagi orang yang langsung keluar dari kelambu tersebut. Tatangar ini menjadi alat pengesahan pranata bagi masyarakat Banjar meskipun secara logika bisa saja tali kelambu yang putus karena talinya yang sudah tidak kuat. Akan tetapi, masyarakat Banjar sudah meyakini bahwa tatangar ini sebagai tanda akan datangnya bahaya dari kiriman ilmu gaib.

b. Lamun kakanakan garing panas lawan hujung talinganya dingin banar, tandanya kakanakan nitu takana kapidaraan

"Kalau anak-anak sakit panas dan ujung telinganya dingin sekali, tandanya anak-anak itu terkena kapidaraan (sakit akibat diganggu makhluk gaib)."

Dalam masyarakat Banjar dipercayai bahwa apabila ada anak yang sakit panas dan ujung telinganya ketika dipegang terasa dingin sekali, anak tersebut dianggap terkena kapidaraan atau gangguan makhluk gaib. Istilah kapidaraan berasal dari kosakata bahasa Banjar pidara yang merujuk kepada makhluk gaib yang berwatak jahat. Jadi, yang dimaksud dengan kapidaraan adalah seorang anak yang jatuh sakit 
karena telah disapa makhluk gaib berwatak jahat.

Untuk penyembuhan kapidaraan ini dibaca mantra khusus oleh juru sembuh serta ditorehkan tanda cacak burung (bekas jejak kaki burung dara) pada bagian kedua daun telinga anak tersebut. Selain kedua telinga, biasanya kedua telapak tangan dan kaki juga ditorehkan tanda cacak burung pada anak yang terkena kapidaraan. Media yang dipakai untuk menorehkannya adalah kapur sirih bercampur parutan kunyit. Tatangar kapidaraan ini menjadi suatu bentuk keyakinan masyarakat Banjar akan adanya makhluk gaib yang jahat.

\subsection{Fungsi tatangar sebagai alat pendidikan anak-anak}

Tatangar juga mempunyai fungsi sebagai alat pendidikan anak-anak bagi masyarakat Banjar. Berikut hasil analisisnya.

a. Mimpi disasahi hadangan, tandanya tabawa nasi ka dalam kalambu.

"Mimpi dikejar kerbau, tandanya terbawa nasi ke dalam kelambu."

Apabila ada seseorang yang bermimpi dikejar kerbau maka dianggap orang tersebut ketika tidur ada nasi yang menempel di bajunya atau di badannya. Memang tidak ada hubungan langsung antara mimpi dikejar kerbau dengan nasi yang terbawa tidur di dalam kelambu. Akan tetapi, masyarakat Banjar masih banyak yang memercayainya sehingga tatangar ini menjadi tanda atau isyarat yang harus diperhatikan ketika akan tidur. Dengan adanya tatangar ini maka orang tua selalu mengajarkan kepada anaknya bahwa ketika selesai makan harus memperhatikan kebersihan. Jangan sampai ketika tidur terbawa sisa makanan ke dalam kelambu. Anak pun akan mendengarkan dan mematuhi nasihat orang tuanya karena tidak ingin bermimpi dikejar kerbau.

Melalui tatangar ini, orang tua dapat mendidik anak mereka agar selalu menjaga kebersihan, terutama selesai makan. Apalagi ketika akan tidur kita harus dalam keadaan bersih, bebas dari sisa makanan, baik di tangan maupun pakaian. Dengan menjaga kebersihan di tempat tidur dan di dalam kelambu, kita dapat beristirahat dengan nyaman. Dengan demikian, tatangar ini memiliki fungsi yang sangat penting dalam mendidik anak-anak agar senantiasa menjaga kebersihan.

b. Bila ada kambang mawar di halaman rumah, tandanya parajakian.

"Bila ada bunga mawar di halaman rumah, tandanya murah rejeki."

Masyarakat Banjar memercayai tatangar apabila menanam bunga mawar di halaman rumah, tandanya akan mendatangkan rezeki atau murah rezeki bagi pemilik rumah tersebut. Di halamanhalaman rumah penduduk, terutama di daerah Martapura banyak masyarakat yang menanam bunga, seperti mawar, melati, dan kenanga. Bunga-bunga tersebut dijual kepada para penjual kembang rampai.

Tatangar ini mampu menjadi sarana mendidik anak agar senantiasa rajin menanam tanaman di halaman rumah. Selain tanaman mawar membuat halaman menjadi indah dan sedap di pandang mata, juga dapat menjadi penghasilan keluarga. Dengan menanam bunga mawar di halaman rumah, tentunya akan mendatangkan rezeki karena harga bunga mawar sendiri lebih mahal dari bunga lainnya yang dibuat untuk kembang rampai.

c. Babinian nang barambut panjang, tandanya urangnya panyabar lawan talaten. 
"Perempuan yang berambut panjang, tandanya orangnya penyabar dan telaten."

Masyarakat Banjar menganggap bahwa apabila ada perempuan yang mempunyai rambut panjang, tandanya orang tersebut penyabar dan telaten. Perempuan Banjar lebih senang mempunyai rambut panjang karena keyakinan mereka yang dianggap sabar dan telaten serta akan cepat dilamar. Bagi, perempuan Banjar, memiliki rambut yang indah akan menjadi idaman bagi laki-laki. Anggapan ini berkembang sejak dulu sehingga banyak perempuan Banjar yang memanjangkan dan merawat rambutnya.

Memang, tidak ada kolerasi antara perempuan yang memiliki rambut panjang dengan sifatnya. Akan tetapi, kepercayaan masyarakat Banjar ini dapat dijadikan sarana dalam mendidik anak. Ketika seorang anak perempuan yang memiliki rambut panjang, tentunya anak tersebut merupakan orang sabar, telaten, dan rajin merawat rambutnya hingga panjang. Tatangar ini menjadikan anak perempuan agar bisa merawat diri, terutama rambut yang menjadi mahkota perempuan.

\subsection{Fungsi tatangar sebagai alat pemaksa dan pengawas agar norma-norma masyarakat akan dipatuhi anggota kolektifnya}

Sastra lisan Banjar tatangar juga mempunyai fungsi sebagai alat pemaksa dan pengawas agar norma-norma masyarakat akan dipatuhi anggota kolektifnya. Berikut hasil analisisnya.

a. Lamun kada sangaja talanggar kucing sampai baluka-luka, maka nang malanggar cagar takana calaka kacuali kucing nitu diubati sampai waras lukanya.

"Kalau tidak sengaja tertabrak kucing sampai luka-luka, maka yang melanggar akan terkena celaka kecuali kucing itu diobati sampai sembuh lukanya."

Bagi masyarakat Banjar, kucing merupakan hewan peliharaan yang harus disayangi dan dipelihara dengan baik. Mayoritas masyarakat Banjar yang muslim ini begitu memercayai bahwa kucing sebagai hewan kesayangan Nabi Muhammad saw. harus dijaga dengan baik. Bahkan, masyarakat Banjar menganggap hewan ini akan mendoakan orang yang memeliharanya agar mendapat rezeki yang berlimpah dan senantiasa dalam keadaan selamat.

Ketika ada seseorang yang tidak sengaja menabrak kucing sampai hewan tersebut mengalami luka-luka, orang tersebut langsung mengobati kucing itu hingga sembuh. Ada anggapan bahwa apabila orang yang menabrak kucing tersebut tidak mengobati, dia akan mendapat celaka sehingga masyarakat Banjar begitu takut untuk melukai kucing. Jadi, siapa pun yang tidak sengaja menabrak kucing harus mengobatinya hingga sembuh dan apabila kucing tersebut mati, orang yang telah menabrak kucing tersebut harus menguburkannya dengan layak.

Melalui tatangar ini diketahui bahwa masyarakat Banjar begitu memercayai bahwa kucing merupakan hewan yang begitu diistimewakan sehingga kucing menjadi hewan peliharaan yang ikut tinggal serumah dengan pemiliknya. Kalaupun ada seseorang yang tidak sengaja menabrak kucing, dia akan bertanggung jawab atas perbuatannya tersebut dengan mengobati hingga sembuh. Dengan demikian, masyarakat begitu mematuhi norma-norma dalam kehidupan masyarakat Banjar.

b. Lamun ada kanakan halus nang rancak gagaringan, tandanya kanakan nitu kabaratan ngaran. "Kalau ada anak kecil yang sering sakit-sakitan, tandanya 
nama yang diemban anak itu terlalu berat."

Tatangar lamun ada kanakan halus nang rancak gagaringan, tandanya kanakan nitu kabaratan ngaran "kalau ada anak kecil yang sering sakit-sakitan, tandanya nama yang diemban anak itu terlalu berat" sudah mendarah daging dalam kehidupan masyarakat Banjar. Melihat dari pengalaman keluarga ataupun teman yang anaknya sering sakit-sakitan karena ketika memberikan nama kepada anaknya tidak melalui perhitungan. Oleh karena itu, biasanya masyarakat Banjar sebelum memberikan nama anak maka dihitung terlebih dahulu melalui perantara ulama. Hal ini menghindari anak agar tidak mengemban nama yang terlalu berat. Kalau pun sudah terlanjur atau salah hitung dan anak sering sakit-sakitan, biasanya nama anak tersebut langsung diganti. Tentunya penggantian nama anak tersebut melalui perantara ulama.

Masyarakat Banjar memercayai pemberian nama kepada anaknya melalui perantara ulama atau tuan guru. Biasanya, orang tua menyodorkan beberapa pilihan nama, kemudian ulama akan memilihkan salah satu nama yang dianggap sesuai dengan anak dan orang tuanya. Adapula, orang tua yang datang langsung kepada ulama untuk meminta langsung nama yang sesuai bagi anaknya. Pemberian nama melalui perantara perhitungan ulama ini diharapkan mengandung doa dan harapan yang baik bagi anak. Dengan demikian, masyarakat begitu mematuhi norma-norma dalam kehidupan masyarakat Banjar yang masih berlaku.

\section{Penutup}

\subsection{Simpulan}

Berdasarkan data penelitian yang telah dikaji terhadap fungsi sastra lisan Banjar tatangar dapat disimpulkan bahwa terdapat empat jenis fungsi sastra lisan
Banjar tatangar yang digunakan, yaitu(1) fungsi tatangar sebagai sebuah bentuk hiburan; (2) fungsi tatangar sebagai alat pengesahan pranata-pranata dan lembaga-lembaga kebudayaan; (3) fungsi tatangar sebagai alat pendidikan anak-anak; dan (4) fungsi tatangar sebagai alat pemaksa dan pengawas agar norma-norma masyarakat akan dipatuhi anggota kolektifnya.

\subsection{Saran}

Berdasarkan hasil penelitian disarankan untuk melakukan penelitian tentang sastra lisan Banjar tatangar yang lebih mendalam lagi, seperti kajian dari sistem tanda semiotik. Disarankan penelitian ini dapat dijadikan bahan acuan bagi penelitian berikutnya untuk mengkaji tentang fungsi sastra lisan Banjar tatangar. Mengingat, kajian mengenai tatangar ini belum banyak diteliti.

\section{Daftar Pustaka}

Amir, Adriyetti. 2013. Sastra Lisan Indonesia. Yogyakarta: Andi.

Arikunto, S. 2006. Prosedur Penelitian: Suatu Pendekatan Praktik. Jakarta: Rineka Cipta.

Astika, I Made dan I Nyoman Yasa. 2014. Sastra Lisan Teori dan Penerapannya. Yogyakarta: Graha Ilmu.

Bartlet, F.C. 1965. "Some Experiment on the Introduction of the Folklore". Dalam A Dundes (ed). The Study of Folklore. Englewood, N.J.: Prentice Hall. 243--258.

Danandjaja, James. 2002. Folklor Indonesia, Ilmu Gosip, Dongeng, dan Lain-lain. Jakarta: Grafiti Press.

Endraswara, Suwardi. 2009. Metodologi Penelitian Folklor: Konsep, Teori, dan Aplikasi. Yogyakarta: Medpress. -. 2013. Metodologi Penelitian Sastra: Epistemologi, Model, 
Teori, dan Aplikasi. Yogyakarta: Buku Seru.

Hapip, Abdul Djebar. 2001. Kamus Banjar Indonesia. Banjarmasin: Grafika Wangi Kalimantan.

Hutomo, Suripan Sadi. 1991. Mutiara yang Terlupakan: Pengantar Studi Lisan. Jawa Timur: Hiski.

Ikram, Achadiati. 2015. "Beraksara dalam Kelisanan". Dalam Pudentia, MPSS (ed.). Metodologi Kajian Tradisi Lisan. Jakarta: ATL Bekerja Sama dengan Yayasan Pustaka Obor Indonesia.

Koster, G. L. 2015. "Kaca Mata Hitam Pak Mahmud Wahid atau Bagaimanakah Meneliti Puitika Sebuah Sastra Lisan?’. Dalam Pudentia, MPSS (ed.). Metodologi Kajian Tradisi Lisan. Jakarta: ATL Bekerja Sama dengan Yayasan Pustaka Obor Indonesia.

Mugeni, Muhammad, dkk. 2008. Kamus Indonesia-Banjar Dialek Kuala. Banjarbaru: Grafika Wangi Kalimantan.

---------. 2009. Tatangar atau Wahana Banjar. Banjarbaru: Grafika Wangi Kalimantan.

Musdalipah, dkk. 2008. Kamus Bahasa Banjar Dialek Hulu-Indonesia. Banjarbaru: Grafika Wangi Kalimantan.
Nurgiyantoro, Burhan. 2012. Teori Pengkajian Fiksi. Yogyakarta: Gadjah Mada University Press.

Sudikan, Setya Yuwana. 2001. Metode Penelitian Sastra Lisan. Surabaya: Citra Wacana.

Sugiyono. 2010. Metode Penelitian Pendidikan Pendekatan Kuantitatif Kualitatif. Bandung: Alfabeta.

Sunarti, Sastri. 2013. Kajian Lintas Media Kelisanan dan Keberaksaraan dalam Surat Kabar Terbitan Awal di Minangkabau (1859-1940-an). Jakarta: KPG.

Taum, Yoseph Yapi. 2011. Studi Sastra Lisan Sejarah, Teori, Metode dan Pendekatan Disertai Contoh Penerapannya. Yogyakarta: Lamalera.

Vansina, Jan. 1985. Oral Tradition as History. Madison: The University of Wisconsin Press.

Wahyono, Parwatri. 2015. "Hakikat dan Fungsi Permainan Ritual Magis Nini Thowok bagi Masyarakat Pendukungnya: Sebuah Studi Kasus di Desa BanyumudalGombong". Dalam Pudentia, MPSS (ed.). Metodologi Kajian Tradisi Lisan. Jakarta: ATL Bekerja Sama dengan Yayasan Pustaka Obor Indonesia. 